\title{
Design and the Question of Aesthetics
}

\author{
Carsten Friberg, \\ Department of Communication, Aalborg University, Denmark
}

\begin{abstract}
In the article an approach to aesthetics is suggested with the focus on the education of the designer rather than on the outcome of the design. Design is taken to be an interpretative intervention into a social context which requires a sensibility for the context. The forming of this sensibility is the goal of an aesthetic education. Through discussions of different approaches to aesthetics like Grant Kester's dialogical aesthetics and Kant's critique of the faculty of judgement, it is emphasized how sensibility as the key focus of aesthetics rather than art and beauty makes the ability to manoeuvre in the social context a central issue of aesthetics. As the argument goes the link to an aesthetic education is understood as an education of our senses through cultural products, which is also a link to a perspective that appears to be absent in present debates on aesthetics in relation to design. Taking up this approach to aesthetics is to suggest a more valuable view on aesthetics in relation to design and educational aspects of the designer's competences.
\end{abstract}

Keywords: aesthetics, sensibility, education, philosophy of design, hermeneutics

\section{INTRODUCTION}

What happens to aesthetics when we talk about strategic design? I will take this question as an opportunity to introduce a different perspective in the aesthetic discourse: both a change in focus from the product to the producer and also a change from a dominating perspective in art, artistic qualities and beauty to sensorial knowledge. In short, I suggest considering what happens when we focus on aesthetics in relation to education, what I in the following will call aesthetic education.

When making aesthetic education the central point I must emphasize that the focus is not on how design can contribute to educating a broader public through aesthetic means; my concern is for the aesthetic education of the designer! Such an education is not the training of artistic judgement or taste but the training of a sensibility towards the surroundings in general. I wish to put any discussion about aesthetic quality aside and only focus on our ability to detect and sense different social relations and cultural situations we find ourselves acting in.

I will see design as an intervention in a social context. Such interventions demand more of the designer than a flair for the aesthetic outcome; it requires a training of the designer's social skills - a training of sensibility and the faculty of judgement. With a growing interest in interactivity and participation as well as manoeuvring in the fuzzy end of planning and organization, comes also an interest in how to deal with these matters. It has motivated new methods in the design curriculum such as ethnographic methods. Aesthetics is absent in this context due to its dominant focus on art and beauty but with a focus in aesthetics on sensibility and judgement this can be different.

The point is that when designers intervene and when they invite users to a participatory process this has two sides: One is the invitation of others to participate in the process; another the designer's interpretation of the feedback from the participants. To invite is to find the most appropriate way of addressing the other and to establish a dialogue as a true dialogue, one in which we are prepared to be surprised by the answers. To be surprised by the response is also a virtue of interpretation which should not be about confirming ideas of what is in the other's utterings but to listen and find what one did not know beforehand. Both invitation and interpretation are very demanding and require a highly developed sensibility, what I suggest to be the outcome of aesthetic education. Or, to give another example, introducing cultural theory to approach one's needs and desires "is about thinking differently" (Satchell, 2008, p. 23). But my point about introducing aesthetics is not about thinking, it is not about theoretical based instruments for analysing; it is about taking action, about practice. 
My main question concerns how the designer's sensibility for the context of a designerly intervention and activity comes about and my question is thus of a philosophical kind more than a practical. This question is not restricted to strategic design as my opening suggested; it concerns all forms of design that intervene in social contexts. However, the question about strategic design can perhaps underline the different approach to aesthetics that I suggest to take. The crucial point is the need for the designer to interpret the situation of the designerly intervention by use of knowledge outside the core competences of design. Interpreting a context for intervention is not depending on factual knowledge of the cultural, organizational, social or political kind, but on our faculty of judgement which depends on our practice of social skills acquired through our sensorial and bodily, i.e. aesthetic, involvement in the world. The central argument, thus, is to reformulate aesthetics in the light of sensorial knowledge and to offer this as a perspective for design where aesthetics emphasizes the education of the designer's sensorial skills.

\section{A BRIEF CHARACTERISATION OF DESIGN}

There are many short definitions of design to be found. Design can be seen as the process by which we "[devise] courses of action aimed at changing existing situations into preferred ones" (Simon, 1996, p. 111); or "[d]esign is the conscious and intuitive effort to impose meaningful order" (Papanek, 1991, p. 4 , italic in original).

Much can be said for and against short definitions of this kind. Being short they give us an idea, but they are also too open and do not exclude much. Simon's definition can also be applied to war and Papanek's can include philately. Perhaps some will have reasons for a very inclusive definition but it is rarely optimal when the inclusiveness is at the price of precision. To do justice to the definitions above, they come from books and will have to be read in context; it is not fair to simply let them represent the authors' opinions without further comments. My reason to quote them, however, is that they are widely used and draw attention to design as an activity intervening in specific contexts. ${ }^{1}$

\section{Despite the incompleteness of short definitions} I will suggest yet another short characterisation relying on an Italian definition from the 17th century. Design, then written disegno, is a word consisting of three parts: di-segn- 0 of which the first and the last gives the word Dio, God, and the middle means sign. Disegno thus includes the additional meaning, apart from drawing, that it is the sign from God in us. This is what Zuccari wrote in 1607, in L'idea de' pittori, scultori ed architetti. (Panofsky, 1993, p. 49)

It may be difficult to have it repeated in the 21st century; however, there is a point in drawing a parallel. If we say that God was a certain perspective, a certain interpretation of the world, then it seems reasonable to say design is a sign in us from the world we act within. Or we can choose a more modern version and say: "[the fate of design] lies within the framework of culture as a whole" (Buchanan, 2010, p. 13); which does not mean a determining frame but the complex totality of our actions and the frames for these. "We are all embedded in the course of a culture that is not fixed and complete. Culture is what we do individually and together through our intentional operations and projects" (ibid., p. 25).

The idea is to say the world is an interpretation or a perspective; world signifies the place we belong to like the etymology of the word reveals, coming from Old Norse "verold/wërold" which is a combination of "verr/wër", man, and "old", age. World is the age of man, the age in which we transform things around us through our actions in contrast to the world of gods or heaven which is perfect and outside our reach. In this sense the designer is still an instrument for the world and the world acts through the designer as the frame and conditions for interpretation. Design is an interpreting intervention that makes a difference. It is an intervention based on a sensibility for the context of intervention and with the intention of creating a specific modification. The training of this sensibility is a key element in aesthetics.

\section{AESTHETICS}

The majority of discourses on aesthetics are about art, artistic qualities, and beauty. Hegel noticed in the opening lines of his lectures on aesthetics held between 1817 and 1829 that aesthetics had now become the title for lectures on beauty and art. Whether aesthetics is approached from an interest in how beauty and art became the issue followed by reflections on what roles art may have in contemporary culture like Odo Marquard does $(1989$, p. 113 f.), or systematically with an interest in a definition of art as in Stephen Davies (1991, p. $107 \mathrm{f}$.), it is art and issues related to art like creativity that become the focus. It is, then, no surprise to find a suggestion for "viewing Design Thinking as [an] aesthetic process of innovation" to be a "creative process, requiring creative practices for creative outcomes" (Lundberg \& Pitsis, 2010, p. 278). A turning point in the process is here the prototypes 
“being a core element in Design Thinking as an aesthetic embodiment of the complex, contradicting, paradoxical and new" (ibid., p. 281). It is the sensemaking of social experiences because the "sense based experiences embodied in prototyping grounded interactions facilitate creativity, -- and thus, they enhance the generative process" (ibid., p. 284).

I will not argue whether this is true or not, only use it as an example illustrating the widespread understanding of aesthetics related to artistic products or processes. In the example, the prototype carries the weight of aesthetics not as something artistic but as a sensuous object which, as sensuous, enables a creative progression. I can only agree when it is said that "what matters, is the emotional experience that is conveyed by interaction with the product, and not the product as a serviceable tool" (ibid., p. 285). What I miss, however, is an elaboration on what it implies when the authors state that "exploring Design Thinking as aesthetic process innovation means to investigate which skills and assets are required in leadership practices in such aesthetic processes" (ibid., p. 284). More is needed than referring to creativity and "sense based experiences".

This seems to be the issue when Ross \& Wensveen state that "aesthetics can be a powerful design driver that helps connect dynamic form, social and ethical aspects", for which they "argue that once we start designing the aesthetics of interactive behavior, a social and ethical dimension is introduced as well" (Ross \& Wensveen, 2010, p. 3, italics in original). The linking of aesthetics to beauty they rightly notice to be in itself too little to determine or at least convey the intended outcome of a situation; "a beautiful product is of little use if it elicits unpleasant, inappropriate, ugly or even inhumane interactions" (ibid.). They draw attention to the important fact that "[ $t]$ he experience of aesthetics depends on a broad range of sociocultural factors, such as people's values, personality, situation and history" (ibid., p. 4). However, it is difficult to see how far this is intended to be taken from the experiment that follows. It includes the use of dancers for designing an intelligent reading lamp to profit from the dancers' use of "emotional, cognitive and social skills in their creative process" where "[t]he Choreographies created by the dancers sought to elicit value-related interactions with the participants" (ibid., p. 6). The sensibility of the dancers towards specific social relations is the motivation for drawing on their competences. Instead of sketching different possible and imagined positions of the lamp, the postures of the dancers responding to the environment is used. But the dancers are only acting out intelligent lamps using their bodily training to respond to the situation. Their sensibility is in no way characterized or in any form conveyed to the designers who are only observers and thus exercising a classical distanced description of the dancer's physical acts and not entering or appropriating their sensibility. ${ }^{2}$

The introduction of socio-cultural factors is crucial even if the experiment is itself too narrow for really unfolding this theme. The authors themselves notice that they "took only a limited part of the social context into account and simplified it for experimental reasons" (ibid., p. 10). Despite its shortcomings, it earns interest for including social aspects into design through an aesthetic approach, namely through the sensorial, emotional, and social skills of the dancers. However, it still leaves the core of the issue untouched, namely how these skills of the dancers are enriching the design process and the designer's skills. The dancers could have provided the designers not only with material for the specific work, but also with social skills, though this may require participation of the designers through dancing.

\section{KESTER'S COMMUNICATIVE AESTHETICS}

Before saying more about the social skills in the design process I will touch upon some aesthetic and philosophical discussions of relevance for combining aesthetics with the sensorial and social skills. Within aesthetics we find discussions about art projects that intervene in social contexts such as works done by art groups like Superflex, Wochenklausur and Yes Men (cf. Thompson \& Sholette, 2004). Here the concern of aesthetics is becoming relational (Bourriaud, 2002) or about communication (Kester, 2004) where the ability of the artist to enter a specific situation and bring about some intended reactions becomes a key issue for the artist. Rather than the standard debate about creativity, artistic qualities, and the capability of evoking an aesthetic pleasure, this invites us to investigate how interactivity is established and how prototypes communicate as objects performing a specific need in a specific situation.

An interesting contribution in the recent aesthetic approach to these matters is the one given by Grant Kester. Through an illuminating exposition of some central issues in aesthetics since the middle of the 20th century, represented by figures like Clive Bell, Roger Fry, Clement Greenberg, and Michael Fried, he draws attention to the elitist view on aesthetics dominating the aesthetic discourse (Kester 2004, p. $31 \mathrm{ff}$.). The focus is on developing an aesthetic critique based on a still more refined ability to make 
distinctions as we see in Greenberg: "it [the work of art] should be difficult rather than easy" (ibid., p. 43). ${ }^{3}$ Kester can state briefly: "modern critics have displayed a singular hostility to artworks that solicit the viewer's interaction in a direct or accessible manner" (ibid., p. 82).

Kester then turns to, among others, Jürgen Habermas for a more nuanced and open approach to aesthetic products. This approach forces us to articulate views we wish to share with others "more systematically, to anticipate and internalize our interlocutor's responses" (ibid., p. 110). The view on art becomes "one defined in terms of openness, of listening ... and of a willingness to accept a position of dependence and intersubjective vulnerability relative to the viewer or collaborator" (ibid.). A strength Kester finds in Habermas' view is how it draws attention to the formation of the aesthetic opinion rather than to our ability to perform in accordance with a set of existing rules. "Discourse is not simply a tool to be used to communicate an a priori 'content' with other already formed subjects but is itself intended to model subjectivity" (ibid., p. 112).

Kester is no follower of Habermas; he raises critical questions about the excessive faith in the rational discussion and lack of sensibility to the differences among the participants in the dialogue which seems to characterize Habermas' view. It is not clear why we become convinced by true understanding and not rhetorical attrition, which summarizes most of the criticism (ibid., p. 113). Therefore he moves to a more nuanced understanding of the complexity of communication and emphasizes that it is important to "situate a given discursive statement in the specific material condition of the speaker" (ibid.) and to understand that "a connected knowledge is grounded in our capacity to identify with other people" (ibid., p. 114).

In agreement with Kester on the last points I wish to move in a different direction and draw attention to how a focus on dialogue and communication can take advantage of a hermeneutic approach which will eventually bring us to the aesthetic education.

\section{HERMENEUTICS}

Communication always belongs to a context and the context will have significant impact on how communication will unfold. But to enter the context seems to be the heart of the matter for which I believe it is to the benefit of the discussion to take a look at hermeneutics and the hermeneutical circle. It draws attention to the mutual dependency of parts and the whole in our understanding (Gadamer, 1988). We are familiar with this in many daily situations, such as when speaking; the meaning of a sentence determines the single parts of it and they in return determine the meaning of the sentence. When part and whole are determining each other the question becomes how we step into this circle in the first place. We cannot, for obvious reasons, begin at the beginning of a circle.

To throw light over our entrance into the circle we can turn to the concept of "divination" as introduced by Friedrich Schleiermacher in the early 19th century. Problematic as the word may sound, divination is about our ability to act in accordance with others through guesses and imitation. We repeat words and actions of others in forms we are familiar with and begin to understand because we appropriate and make fusions between what we already know and the new information we receive and we also discover new perspectives and directions for our understanding. Divination is no simple reproduction, nor a psychological ability to step into the other's place; it is what we recognize from, for example, a social game where we imitate what we see and guess what will be the best following step to make. Through that we slowly begin to understand the rules. Later when we reflect on what we did, we may see how we sometimes imitated rightly without knowing because we did not fully understand at the time of our acts; sometimes we chose things inappropriate for the situation and only discover our mistakes when they fall through. Through imitation we acquire experiences and knowledge, which we apply to the knowledge we already possess, and we expand our knowledge and move into new understandings (Schleiermacher, 1988, p. 326 f.; cf. Bowie, 1995, p. 163 ff.). ${ }^{4}$

\section{AESTHETIC JUDGEMENT}

Our ability to intervene in different situations based on our previous knowledge, to bring this knowledge into play, to imitate and be creative in applying the imitation, and to see new perspectives are all components of aesthetics. Imaginative disposition, good memory, foresight and expressive talent are some of the features of the sensorial training that A. G. Baumgarten gave the name of aesthetics (Baumgarten, 2007 [1750/58], p. 30 ff.). Also, imitation has a long career in aesthetics from antique ideals of mimesis to modern forms of imitatio, and our ability to imitate and to make the best guesses about the behaviour of others is based on our experiences and imaginative faculty, the constitutive elements of what Kant names the reflecting judgement. 
Judgement about others and social relations can be related to taste. Kant devotes a substantial part of his Critique of Judgement to the judgement of taste. For Kant it is not the final purpose of his investigation but only a means for establishing the validity of our faculty of judgement as such, but for us it attracts interest as we through it demonstrate our ability to judge correctly within a specific community. My appreciation of something is not simply an expression of an arbitrary feeling but it is an opinion I hope there is consensus about because we share, in a specific community, a background that makes us feel similar about cultural products. The judgement of taste demonstrates a relation to a cultural context by making explicit how we respond to cultural products and, Kant writes, "[w]e could even define Taste as the faculty of judging of that which makes universally communicable, without the mediation of a concept, our feeling in a given representation" (Kant, 1974 [1790/99], § 40, italics in original).

Taste expresses a sensorial relation to something and our evaluation of it, and we expect others to give their consent. This points to a difficulty Kant calls the antinomy of taste; we can quarrel about taste but we cannot have a dispute or a controversy as the latter is expected to be settled by referring to concepts (ibid., § 56). So how is it possible to quarrel and expect to settle the quarrel in the end by agreeing to the judgement when we cannot appeal to any concepts?

Without going into the details of how Kant solves this antinomy, we can take up a single point namely that we can agree on "our feeling in a given representation". For Kant, the judgement of taste expresses a feeling of pleasure or displeasure. This feeling is not caused by an object but originates from the harmonious play of our faculties of knowledge, namely between understanding and imagination. We imagine something as if the imagination was led by a concept, but in fact it has been produced freely by the imagination (ibid., § 9). ${ }^{5}$

Sometimes, the imagination is not unbridled but we imagine something as if there is a concept. What we imagine is then something reasonable which the purely imaginative is not; and what we imagine is not coming out of nothing but from the material of our experiences. This is why we can expect an agreement to our judgement of taste. If we share experiences and we do because we share educational background - our imagination will work in parallel ways, drawing on memories of a similar kind. If the feeling of pleasure is caused by the harmony of imagination and understanding, which of course is a debateable premise, we do feel and respond to cultural products in similar ways. What Kant demonstrates is how the judgement of taste is important for the social aspect; it is a judgement about how we perceive cultural products based on our educational background.

The purpose of Kant's treatment of the aesthetic judgement is to investigate, as the title of the book says, our faculty of judgement. This is of importance in situations wherein we seek to find rules for the right code of conduct. We have no manual to look into for determining a given situation; we can only look into our experiences - we look back on ourselves i.e. reflect - and find what seems appropriate. If we share experiences we will also come up with similar ideas of how to perceive situations and what behaviour to perform. We can be mistaken, and sometimes are; we can disagree and argue about what to do, but we expect to be able to establish agreement about the right behaviour not by appealing to a strict proof but by reaching agreement after a reasonable debate.

With Kant we can say that the judgement of taste is a demonstration of our sensibility towards a context and that the education of this sensibility is crucial.

\section{THE AESTHETIC EDUCATION}

The social dimension of the judgement of taste as an expression of a feeling which is "universally communicable" is thus offering a connection fruitful for answering the question of aesthetics in relation to design. Rather than a discussion about aesthetic qualities such as beauty and creativity we should focus on the sensibility of the situation which design intervenes into.

The need for sensibility and knowledge of situations is, of course, no surprising conclusion and my intention is not to end here but to emphasize the necessity of an education of the senses. With Kant in mind, it is the need to participate in and act within different situations. I may come a long way with reading about or being a spectator to different cultural formations; and I may come a long way if the reading is poetry and literature, which can give the best possible understanding of what lies behind the viewable actions. But the definitive aspect of developing our sensibility towards situations is not knowledge of but practice with them.

If we once again take the example of Ross \& Wensveen from above using dancers in investigating the social dimension of an intelligent reading lamp where "the dancers sought to elicit valuerelated interactions with the participants" (Ross \& Wensveen, 2010, p. 6), my questions would be: Why 
are only the dancers involved? Why not the designers themselves? In the example, the dancers can deliver some material for the designers to work with, but the value of the material that would be the outcome of the designers stepping into performing with the dancers may be greater. It would be to feel for themselves some of the situations detected and demonstrated by the dancers thus acknowledging the value of experiences made rather than experiences conveyed.

This is a consequence similar to what Richard Shusterman asks for in his "somaesthetics" aesthetics with special regard to the body, to somatic elements (Shusterman, 2000, p. 262 ff.). Emphasizing the importance of the body for our perception and interpretation, he asks us to be aware of how our bodily behaviour is of importance as to how we find ourselves in relation to other people and what games of power we participate in. An example could be how a job interview is performed favouring certain attitudes of aggressive self-promotion and, perhaps, masculine values of power (Shusterman, 2008, p. 22). The interesting and perhaps also provocative aspect of Shusterman's somaesthetics is the conclusion he brings it to: we can find many analyses of the importance of the body in contemporary academic literature, what he labels analytic somaesthetics, (Shusterman, 2000, p. 271 f.), but we should also include the traditions of working with the body like yoga, bodybuilding, T'ai chi chu'an, etc., called pragmatic somaesthetics (ibid., p. $272 \mathrm{ff}$.), and finally not only theorize and talk about it, but do something ourselves and enhance the bodily awareness through a practical somaesthetics (ibid., p. 276).

I think we should take Shusterman seriously and ask the designer to get involved in social matters by actually performing in situations and also to perform in ways not bound exclusively to the designer's training. The challenge to the designer should not be less than the one Shusterman gives the philosopher when he asks them to step out on the floor and do bodily exercises - especially when design is taken to be much more integrated into everyday life and reality than philosophy is usually taken to be. What Shusterman suggests is to increase our awareness of our bodily presence to be able to perform intended acts better. A problem, for example, that philosophers can share with designers as well as most of the western population is muscular tensions in the neck caused by our working with computers or similar chair-based activities. Such tensions and pains are not only a matter of discomfort, but they also affect our perception of the work, perhaps making us more insisting and stubborn or making us pay less attention to details in order to get it done or even making us feeling less open and curious because we are irritated and disturbed by our bodies.

This is still hardly a conclusion that will challenge many designers who will refer to creative selfunderstanding and training as designers. However, I believe it is more challenging in different ways than it may sound. Firstly, I doubt that the amount of bodily exercises and dance that is practiced in the design schools is impressive. This is not about promoting dance for the curriculum of design educations; a bodily training is no universal means but could be appropriate in specific situations. Dance has, however, been considered an integrated part of a classical aesthetic education which is a formation [Bildung] of our moral character as well as our appearance in body, speech, gesture, attentiveness, etc., making it possible to recognize different social games and participate in them. It was not meant to be for the fun of dancing or for being able to promote oneself in the higher society that young noblemen were practicing dance but for learning how to behave, move, express oneself bodily etc. ${ }^{6}$

My example with dance should not be understood as my wish simply to include dance, music, literature, etc. into the design education but as a call for reflection on how such elements in the classical aesthetic education, meant for training our sensorial knowledge, could be of importance and could be a different way of discussing aesthetics in design. They are interesting for their purpose of training the social skills needed for acquiring the proper sensibility towards the context of the designerly intervention - basically to be able to communicate with the users and clients. Though the use of participatory methods are a prosperous way of including the users into the process of designing, it also requires an element of participation that goes the other way: The interpretation of feedback is only successful if it is based on a high level of sensibility towards the other and not on fixed schemes, models, and prejudices. The idea of insisting on sensorial and bodily training is to insist on the need for becoming involved in all aspects of the culture the designer finds important to intervene into and this includes acknowledging and respecting the premises of different cultural appearances.

This leads to a second consequence: the challenge of the concept of aesthetics when moving the discourse away from art or beauty related topics. While this is a challenge to habits, it is also an offer. In general it offers a concept fruitful for almost any form of design in dialogue with the surroundings and perhaps 
for seeking ways of avoiding too artistic aesthetic ideals - the designer working within the frame of artes minors. More specifically, it gives an answer to the question of what becomes of aesthetics when design becomes absorbed in planning, strategy and other fields related to engineering and business schools. Skills of interpreting and communicating to specific groups are required for designing service facilities and for designing strategies. And it is exactly for providing such skill that aesthetic education is introduced.

\section{NOTES}

1. They can be accompanied by others and more recent characteristics of design concerned with the design as an effect and intervention producing something rather than itself being a product (Vial, 2010, p. $55 \mathrm{ff}$.); or: "design, stripped to its essence, can be defined as the human capacity to shape and make our environment in ways without precedent in nature, to serve our needs and give meaning to our lives" (Heskett, 2003, p. 7).

2. A similar approach, to use a dancer's experience, is found in Vroman et al., 2011. Here it is about the dancer's spatial experience used for architects and the experiment, which is the beginning of a research project, addresses the question of how to have access to the dancer's experience.

3. Greenberg can say about the Russian peasant confronted with paintings of Repin and Picasso that the peasant will chose Repin; "[the] uncomfortable circumstances in which he lives do not allow him enough leisure, energy and comfort to train for the enjoyment of Picasso. This needs, after all, a considerable amount of "conditioning" ... In the end the peasant will go back to kitsch when he feels like looking at pictures, for he can enjoy kitsch without effort" (Greenberg, 1961, p. 18). Without much doubt, most modern art asks for an education to be appreciated; the difficulty in Greenberg's view is the devaluation of the uneducated. A similar attitude is expressed by Beardsley: “The central task of aesthetic education, as traditionally conceived, is the improvement of taste, involving the development of ... the capacity to obtain aesthetic gratification from increasingly subtle and complex aesthetic objects that are characterized by various forms of unity" (Beardsley, 1982, p. 31).
4. Not unlike the description of the reflective practitioner given by Donald Schön (e.g. Schön 1987, p. $22 \mathrm{ff}$. and $80 \mathrm{ff}$.)

5. Readers of Kant will probably add that we have many causes for feeling pleasure and displeasure and what Kant presents in relation to the aesthetic judgement is a situation of a pure feeling, i.e. it is alone caused by the subjective faculties and not anything external. We also feel pleasure in a good deed or something sensuous, but that is a different matter not serving the purpose of investigating the pure aesthetic judgement which for Kant is to establish the legitimacy of our faculty of judgement as such. For both short and excellent introductions to Kant's aesthetics see Scheer (1997, p. 73 ff.) and Bowie (1995, p. 15 ff.)

6. “[T]he greatest advantage of dancing well is, that it necessarily teaches you to present yourself, to sit, stand, and walk genteelly" (Lord Chesterfield, 2008, p. 99).

\section{REFERENCES}

Baumgarten, Alexander G. (2007). Ästhetik I-I/ (Dagmar Mirbach, Trans.). Hamburg: Felix Meiner. (Original work published 1750/58).

Beardsley, Monroe C., Wreen, Michael J., \& Callen, Donald M. (1982). The Aesthetic Point of View: Selected Essays. Ithaca, N.Y.: Cornell University Press.

Bourriaud, Pierre. (2002). Relational Aesthetics. Paris: Presses du reel.

Bowie, Andrew. (1995). Aesthetics and Subjectivity: from Kant to Nietzsche. Manchester/New York: Manchester University Press.

Buchanan, Richard. (2010). Branzi's dilemma. Design in contemporary culture. In Richard Buchanan, Dennis P. Doordan \& Victor Margolin (Eds.), The designed world: Images, objects, environments (pp. 13-27). Oxford and New York: Berg.

Chesterfield, Philip Dormer Stanhope, Earl of. (2008). Letters. Edited and with an introduction and notes by David Roberts. Oxford: Oxford University Press.

Davies, Stephen (1991). Definitions of art. Ithaca and London: Cornell University Press.

Gadamer, Hans-Georg. (1988). On the Circle of Understanding (John M. Connolly, Trans.). In John M. Connolly \& Thomas Keutner (Eds.), Hermeneutics versus science? Three German views. Essays by H.-G. Gadamer, E. K. Specht, W. Stegmuller (pp. 68-78). Notre Dame, Ind.: University of Notre Dame Press.

Greenberg, Clement (1961). Art and culture. Critical essays. Boston: Beacon Press.

Heskett, John. (2003). Toothpicks and logos: Design in everyday life. Oxford: Oxford University Press.

Kant, Immanuel. (1974). Kritik der Urteilskraft. Hamburg: Felix Meiner. (Original work published 1790/1799). For English translation is used Kant's Critique of judgement, translated with introduction and notes by J.H. Bernard (2nd ed. revised). 
London: Macmillan, 1914. Available from http://oll.libertyfund. org/index.php?option=com_staticxt\&staticfile=show.php $\% 3 F$ title=1217\& Itemid=99999999 (Accessed 25 June 2013).

Kester, Grant (2004). Conversation pieces. Community + communication in modern art. Berkeley, L.A.; London: University of California Press.

Lundberg, Maria \& Tyrone S. Pistis (2010). Leading ideas: Design Thinking as aesthetic process innovation. In Dorst, Stewart, Staudinger, Paton, Dong eds.: Proceedings of the 8th Design Thinking Research Symposium (DTRS8), Sydney, 19-20 0ctober, 2010, (pp. 277-288).

Marquard, Odo (1989). Aesthetica und Anaesthetica. Philosophische Überlegungen. Paderborn: Ferdinand Schöningh.

Panofsky, Erwin (1993). Idea. Ein Beitrag zu Begriffsgeschichte der älteren Kunsttheorie. Berlin: Wissenschaftsverlag Volker Spiess. (Original work published 1924).

Papanek, Victor J. (1991). Design for the real world: Human ecology and social change (revised 2nd edition). London: Thames \& Hudson.

Ross, Philip R., \& Wensveen, Stephan A. G. (2010). Designing behavior in interaction: Using aesthetic experience as a mechanism for design. International Journal of Design, 4(2), 3-13.

Satchell, Christine (2008). Cultural theory and design: Identifying trends by looking at the action in the periphery. Interactions, 15(6), 23-25.

Scheer, Brigitte. (1997). Einführung in die philosophische Ästhetik. Darmstadt: Primus.

Schleiermacher, Friedrich. (1988). Hermeneutik und Kritik: mit einem Anhang sprachphilosophischer Texte Schleiermachers (4. Aufl.). Frankfurt am Main: Suhrkamp.

Schön, Donald (1987). Educating the reflective practitioner. Toward a new design for teaching and learning in the professions. San Francisco: Jossey-Bass.

Shusterman, Richard. (2000). Pragmatist aesthetics: Living beauty, rethinking art(2nd ed.). Lanham, Md.: Rowman \& Littlefield.

Shusterman, Richard. (2008). Body consciousness: A philosophy of mindfulness and somaesthetics. Cambridge; New York: Cambridge University Press.

Simon, Herbert A. (1996). The sciences of the artificial (3rd ed.). Cambridge, Mass. and London, England: The MIT Press. (Original publication 1961).

Thompson, Nato \& Gregory Sholette (Eds.). (2004). The interventionists. Users' manual for the creative disruption of everyday life. Cambridge, Mass. and London: The MIT Press.

Vial, Stéphane (2010). Court traité du design. Paris: Presses Universitaires de France.

Vroman, Liselotte; Thierry Lagrange, Luiz Naveda (2011). Generating tacit knowledge through motion: A vision on the matter of space. In Kristina Niedderer, Kerstin Mey, Seymour Roworth-Stokes. (Eds.) EKSIG 2011: SkinDeep - experiential knowledge and multi sensory communication. Proceedings of the International Conference 2011 of the DRS Special Interest Group on Experiential Knowledge. University for the Creative Arts, UK. Available from http://www.experientialknowledge. org

\section{CORRESPONDENCE}

Carsten Friberg, Aalborg University, Department of Communication, Strandvejen 1,9000 Aalborg,

Denmark.

E-mail: friberg@hum.aau.dk

Published online 27 January, 2014

ISSN 1749-3463 print/ ISSN 1749-3471

DOI: 10.1080/17493460802480446

(C) 2014 Artifact 